\title{
Efficiency Improvement of PEM Fuel Cells via Humidity Control
}

\author{
Ahmad Haddad ${ }^{1}$, Louay Elsoufi ${ }^{2}$, Marc Mannah ${ }^{1}$ and Hasan Bazzi ${ }^{1}$ \\ 1. School of Engineering, Department of Electrical Engineering, Lebanese International University, Beirut, Lebanon \\ 2. School of Engineering, Department of Mechanical Engineering, Lebanese University, Tripoli, Lebanon
}

\begin{abstract}
PEM (Proton Exchange Membrane) fuel cell is a promising renewable energy source to a wide range of applications for its clean products and high power density. However, controlling its humidity is a challenging problem due to the interdependence of several phenomena contributing in membrane's water content. This work deals with efficiency improvement of PEM fuel cells via humidity control. An innovative strategy of control based on the model of Ref. [1] is proposed. It consists on regulating gas humidification rates according to the power demand so that to minimize power losses. The proposed control takes into consideration constraints related to humidification in order to avoid dry out or flooding of the membrane. Simulations results show that time-phasing between hydrogen and oxygen humidification rates plays an important role in minimizing power losses. The proposed control shows significant improvement in the fuel cell's efficiency up to $20 \%$.
\end{abstract}

Key words: PEM fuel cell, mathematical modeling, humidity control, efficiency improvement.

$\begin{array}{ll}\text { Notations } & \\ A & \text { Area }\left(\mathrm{m}^{2}\right) \\ a_{\mathrm{w}} & \text { Water activity } \\ C & \text { Concentration }\left(\mathrm{mol} / \mathrm{m}^{3}\right) \\ C_{d l} & \text { Double layer capacitance }(\mathrm{F}) \\ C_{g e o m} & \text { Geometrical capacitance }(F) \\ D & \text { Diffusion coefficient }\left(\mathrm{m}^{2} / \mathrm{s}\right) \\ E & \text { Nernst voltage }(\mathrm{V}) \\ F & \text { Faraday constant }(\mathrm{C} / \mathrm{mol}) \\ i & \text { Current }(A) \\ j & \text { Current density }\left(\mathrm{A} / \mathrm{cm}^{2}\right) \\ j_{o} & \text { Exchange current density }\left(\mathrm{A} / \mathrm{cm}^{2}\right) \\ j_{t} & \text { Limit current density }\left(\mathrm{A} / \mathrm{cm}^{2}\right) \\ J & \text { Gas diffusion flux }(\mathrm{mol} / \mathrm{s}) \\ L & \text { Thickness }(\mathrm{m}) \\ P & \text { Pressure }(P a) \\ R & \text { Resistance }(\Omega) \\ R & \text { Gas constant }(\mathrm{J} / \mathrm{mole} . \mathrm{K}) \\ T & \text { Temperature }(\mathrm{K}) \\ V & \text { Voltage }(\text { Volt }) \\ X & \text { Mole fraction } \\ & \end{array}$

Greek-Letters

$\alpha$

Charge transfer coefficient

Corresponding author: Ahmad Haddad, assistant professor, research fields: control systems and renewable energy.

$\begin{array}{ll}\eta & \text { Voltage loss (Volt) } \\ \lambda & \text { Water content }\end{array}$

Subscripts

$\begin{array}{ll}a, \text { an } & \text { Anode } \\ a c t & \text { Activation } \\ b d & \text { Back diffusion } \\ c, c a & \text { Cathode } \\ c o n c & \text { Concentration } \\ e & \text { Electrode } \\ H^{+} & \text {Hydrogen protons } \\ \mathrm{H}_{2} & \text { Hydrogen } \\ \mathrm{H}_{2} \mathrm{O} & \text { Water } \\ \text { in } & \text { Input } \\ \mathrm{M}, \mathrm{m} & \text { Membrane } \\ o & \text { Ohmic } \\ \text { out } & \text { Output } \\ \mathrm{O}_{2} & \text { Oxygen } \\ t & \text { Total }\end{array}$

Superscripts

$\begin{array}{ll}B P & \text { Bipolar plate zone } \\ \text { sat } & \text { Saturation } \\ T C & \text { Triple contact zone }\end{array}$




\section{Introduction}

Fuel cell technology faces many obstacles retarding its marketing such as production cost and lifetime limitation. Among real obstacles is the control of physical phenomena occurring inside the cell in high dynamics of power demand. Particularly, controlling internal humidity of fuel cells is one of the most challenging problems. In fact, several interdependent phenomena contribute in membrane's water content. Placing a humidity sensor is unfeasible since the membrane is extremely thin and the sensor will block gas diffusion. Hence, a control-oriented mathematical modeling of water transport is needed to improve fuel cell's efficiency and lifetime.

Strong dependence and coupling between internal phenomena are the main cause of mathematical modeling limitation in literature. To avoid complexity, most of works focus on studying each phenomenon separately from the others. The existing models could be classified into three main categories:

(1) Static models describing the fuel cell's polarization curve [2-9]. These models are suitable for stationary applications where the operating point do not change rapidly. However, when it comes to dynamic applications these models are not convenient since they cannot follow the rapid change in power demand.

(2) Dynamic linear models such as state space linear models [10-13]. They result from the linearization of nonlinear models around an operating point. Being simple and easy to control are their main advantages. However, these works do not describe precisely highly nonlinear phenomena occurring inside the fuel cell. Results in Ref. [14] show a considerable error between linear models and experimental tests. Therefore, the fuel cell's control in dynamic applications cannot rely on this type of models.

(3) Dynamic nonlinear models that focus on studying each phenomenon separately from the others. For example, in the works of Refs. [15] and [16] electrochemical modeling was not coupled with mass balance modeling. Furthermore, they do not consider the effect of temperature and humidity variations on the output voltage and voltage losses. Other works are based on fuzzy logic and artificial neural networks approaches to model the fuel cell [17-24]. Based on learning techniques, these computational models are not appropriate for fuel cells because they are not deterministic: they are black box; that is internal phenomena are not described. Moreover, model's learning requires time which is not convenient for controlling a critical parameter such as membrane's humidity.

Important works dealing with modeling membrane's water content in transient behaviors are the ones given by Refs. [25] and [26]. In their works, Wang studied the water distribution with respect to the space scale in a three-dimensional model as well as the two-phase flow. Fuller and Newman [27] examined experimentally the water transport number in Nafion 117 membrane and presented the relationship between transport number and electro-osmotic coefficient. Okada et al. [28] modeled the water transport and concentration profile at the anode side.

In summary, the above models do not consider all parameters influencing the membrane's humidity, such as: water mole fractions in hydrogen and oxygen, water production at the cathode as well as the phenomena of diffusion and electro-osmosis between anode and cathode. Furthermore, they do not study the dynamic evolution of the humidity and its influence on the fuel cell's efficiency.

This paper is based on the mathematical model developed in our previous work [1] where the above limitations were covered. In that model all parameters affecting membrane's humidity including gas humidification rates were studied. Effect of humidity on electrical outputs and interactions between charge and mass transport along the fuel cell's components were considered. In this work, an innovative strategy of humidity control is proposed. It consists on 
regulating gas humidification rates according to the power demand so that to improve fuel cell's efficiency.

\section{Mathematical Model}

In a previous paper we have developed a mathematical model that meet the objectives of the control proposed in this work [1]. The model built in Ref. [1] takes into account interactions between fuel cell's internal phenomena as well as their effects on the membrane's humidity. It also permits to regulate the humidity through humidification of input gas. We recall in Table 1 the input/output variables of the model. The inputs are hydrogen flow rate $\left(J_{H_{2}}^{A}\right)$, water mole fractions in hydrogen $\left(X_{\mathrm{H}_{2} \mathrm{O}}^{\mathrm{A}}\right)$ and oxygen $\left(X_{\mathrm{H}_{2} \mathrm{O}}^{\mathrm{O}}\right.$ ), as well as gas pressures $\left(P_{\mathrm{H}_{2}}^{B P}, P_{\mathrm{O}_{2}}^{B P}, P_{\mathrm{H}_{2} \mathrm{O}}^{B P}\right)$ at the bipolar plates zone (BP). At outputs we consider the output voltage per cell $\left(V_{\text {out }}\right)$ and the current density $(j)$.

We recall also the state variables of the model in the following state-space vector:

$$
x=\left[J_{H_{2}}^{T C}, J_{O_{2}}^{T C}, J_{H_{2} O}^{T C}, V_{e}, v_{1}, v_{2}, v_{3}, v_{4}, v_{5}, v_{6}\right]^{T}
$$

where $v_{1}$ to $v_{6}$ are the intermediate variables related to input derivatives $\dot{u}_{1}$ to $\dot{u}_{6}$ [1].

The global state-space model is:

$$
\begin{gathered}
\dot{x}_{1}=\alpha_{2} x_{1}-\alpha_{2} u_{1}+\alpha_{1}\left(K u_{4}-x_{8}\right) ; \\
\dot{x}_{2}=\beta_{3} x_{2}-\beta_{2} u_{1}+\beta_{1}\left(K u_{5}-x_{9}\right) ; \\
\dot{x}_{3}=\gamma_{2} x_{3}-\gamma_{2} u_{1}+\gamma_{1}\left(K u_{6}-x_{10}\right) ; \\
\dot{x}_{4}=-\frac{a_{7} u_{1} x_{4}}{\operatorname{In}\left(a_{8} u_{1}-a_{9} u_{1}^{2}\right)}-a_{10} u_{1} ; \\
\dot{x}_{5}=K^{2} u_{1}-K x_{5} ; \quad \dot{x}_{6}=K^{2} u_{2}-K x_{6} ; \\
\dot{x}_{7}=K^{2} u_{3}-K x_{7} ; \quad \dot{x}_{8}=K^{2} u_{4}-K x_{8} ; \\
\dot{x}_{9}=K^{2} u_{5}-K x_{9} ; \quad \dot{x}_{10}=K^{2} u_{6}-K x_{10} ;
\end{gathered}
$$

Table 1 Input/output variables.

\begin{tabular}{|l|l|}
\hline Inputs & Description \\
\hline$u_{1}: J_{H_{2}}^{B P}$ & Hydrogen diffusion flow \\
\hline$u_{2}: X_{H_{2} O}^{A}$ & Water mole fraction in hydrogen \\
\hline$u_{3}: X_{H_{2} O}^{C}$ & Water mole fraction in oxygen \\
\hline$u_{4}: P_{H_{2}}^{B P}$ & Hydrogen pressure at the BP zone \\
\hline$u_{5}: P_{O_{2}}^{B P}$ & Oxygen pressure at the BP zone \\
\hline$u_{6}: P_{H_{2} O}^{B P}$ & Water pressure at the BP zone \\
\hline Outputs & Description \\
\hline$y_{1}: V_{\text {out }}$ & Output voltage \\
\hline$y_{2}: j$ & Current density \\
\hline
\end{tabular}

$$
\begin{aligned}
& y_{1}=E^{0}+\frac{R_{g} T}{2 F} \operatorname{In}\left[\frac{P_{H_{2}}^{T C} \sqrt{P_{O_{2}}^{T C}}}{P_{H_{2} O}^{T C}}\right]+2 x_{4} \\
& -2 F u_{1}\left(R_{a}+R_{c}+\frac{L_{m}}{A\left(a_{5} \lambda_{m}-a_{6}\right)}\right)
\end{aligned}
$$$$
y_{2}=2 F u_{1}\left[1-\frac{L_{m} C_{g e o m} a_{5}}{A\left(a_{5} \lambda_{m}-a_{6}\right) 2} \frac{d \lambda_{m}}{d t}\right]-2 C_{\text {geom }} \dot{x}_{4}
$$$$
-2 F C_{\text {geom }}\left(K u_{1}-x_{5}\right)\left[R_{a}+R_{c}+\frac{L_{m}}{A\left(a_{5} \lambda_{m}-a_{6}\right)}\right]
$$

$$
-\frac{R_{g} T C_{\text {geom }}}{2 F}\left[\frac{\dot{P}_{H_{2}}^{T C}}{P_{H_{2}}^{T C}}+\frac{\dot{P}_{O_{2}}^{T C}}{2 P_{\mathrm{O}_{2}}^{T C}}-\frac{\dot{P}_{\mathrm{H}_{2} \mathrm{O}}^{T C}}{P_{\mathrm{H}_{2} \mathrm{O}}^{T C}}\right] .
$$

where,

$$
\begin{gathered}
\lambda_{m}=a_{1}+N_{1} u_{2}\left[\frac{a_{2}}{2}-\frac{N_{1} a_{3} u_{2}}{2}+\frac{N_{1}^{2} a_{4} u_{2}^{2}}{2}\right] \\
+N_{2} u_{3}\left[\frac{a_{2}}{2}-\frac{N_{2} a_{3} u_{3}}{2}+\frac{N_{2}^{2} a_{4} u_{3}^{2}}{2}\right] \\
\frac{d \lambda_{m}}{d t}=\left[N_{1} \dot{u}_{2}+N_{3} u_{2}\right]\left[\frac{a_{2}}{2}-\frac{N_{1} a_{3} u_{2}}{2}+\frac{N_{1}^{2} a_{4} u_{2}^{2}}{2}\right] \\
+\left[N_{2} \dot{u}_{3}+N_{4} u_{3}\right]\left[\frac{a_{2}}{2}-\frac{N_{2} a_{3} u_{3}}{2}+\frac{N_{2}^{2} a_{4} u_{3}^{2}}{2}\right] \\
+N_{1} u_{2}\left[-\frac{N_{1} a_{3} \dot{u}_{2}}{2}-\frac{N_{3} a_{3} u_{2}}{2}+N_{1}^{2} a_{4} \dot{u}_{2}+N_{1} N_{3} a_{4} u_{2}^{2}\right] \\
+N_{2} u_{3}\left[-\frac{N_{2} a_{3} \dot{u}_{3}}{2}-\frac{N_{4} a_{3} u_{3}}{2}+N_{2}^{2} a_{4} \dot{u}_{3}+N_{2} N_{4} a_{4} u_{3}^{2}\right]
\end{gathered}
$$




$$
\begin{gathered}
\alpha_{1}=\frac{A D_{H_{2}}}{R_{g} T L} ; \quad \alpha_{2}=\frac{D_{H_{2}}}{L^{2}} ; \quad \alpha_{3}=\frac{R_{g} T L}{A D_{H_{2}}} ; \\
\beta_{1}=\frac{A D_{O_{2}}}{R_{g} T L} ; \quad \beta_{2}=\frac{\beta_{3}}{2}=\frac{D_{O_{2}}}{2 L^{2}} ; \quad \beta_{4}=\frac{1}{2 \beta_{1}} ; \\
\gamma_{1}=\frac{A D_{H_{2} O}}{R_{g} T L} ; \quad \gamma_{2}=\frac{D_{H_{2} O}}{L^{2}} ; \quad \gamma_{3}=\frac{R_{g} T L}{A D_{H_{2} O}} ; \\
\dot{u}_{1}=K u_{1}-x_{5} ; \quad \dot{u}_{2}=K u_{2}-x_{6} ; \quad \dot{u}_{3}=K u_{3}-x_{7} ; \\
\dot{u}_{3}-x_{8} ; \quad \dot{u}_{5}=K u_{5}-x_{9} ; \quad \dot{u}_{6}=K u_{6}-x_{10} ; \\
N_{H_{2}} P_{T_{a n, i n}}^{s a t}
\end{gathered}
$$

Simulation results presented in our previous paper [1] showed that water mole fractions in hydrogen and oxygen have influence on the fuel cell's electrical efficiency. These results are used in the following section to build an appropriate humidity control aiming to minimize power losses inside the cell.

\section{Humidity Control}

We develop in this part a strategy for controlling the membrane's humidity in view of improving its performance. The proposed strategy is based on regulating the membrane water content $\lambda_{m}$ calculated from the state-space model, with respect to $\lambda_{\text {ref }}$ calculated from reference water activities $a_{w, r e f}^{A}$ and $a_{w, r e f}^{C}$. The regulation consists on adjusting water mole fractions in hydrogen $X_{H_{2} O}^{A}$ and oxygen $\mathrm{X}_{\mathrm{H}_{2} \mathrm{O}}^{\mathrm{C}}$ according to the power demand. The proposed control takes into consideration constraints related to humidification in order to avoid dry out or flooding of the membrane.

The suggested regulation process is illustrated by the block diagram in Fig. 1. Indeed, the hydrogen flow rate $u_{1}$ is considered as free input representing the power demanded by the load. The reference water mole fractions $u_{2, \text { ref }}$ and $u_{3, \text { ref }}$ are computed with respect to $u_{1}, a_{w}^{A}$ and $a_{w}^{C}$. The commands related to humidification $\left(u_{2}\right.$ and $\left.u_{3}\right)$, are determined with respect to $u_{2, \text { ref }}$ and $u_{3, \text { ref }}$ plus a correction based on the error calculated between $\lambda_{\text {ref }}$ and $\lambda_{m}$. The latter is computed from the model's state variables, the input $u_{1}$ and the output $y_{1}$.

As is widely used in the literature, the control of the humidity inside fuel cells is realized by fixing a constant reference for water activities $a_{w}^{A}$ and $a_{w}^{C}$ regardless of the operating conditions. In fact, maintaining a constant humidity in case of dynamic power demand, such as in automotive applications, is not optimum as we will show in this work. The remainder of this section is divided into two parts: In the first part, we elaborate the control laws that ensure static water activities regardless of the power demand. In the second part, the evolution of the power demand is taken into consideration when building the control laws.

\subsection{Control for Static Water Activities}

In case of stationary applications, the dynamic of load variation is slow and therefore the power demand can be considered as piecewise constant. Hence, the control objective is to maintain the water activities at 


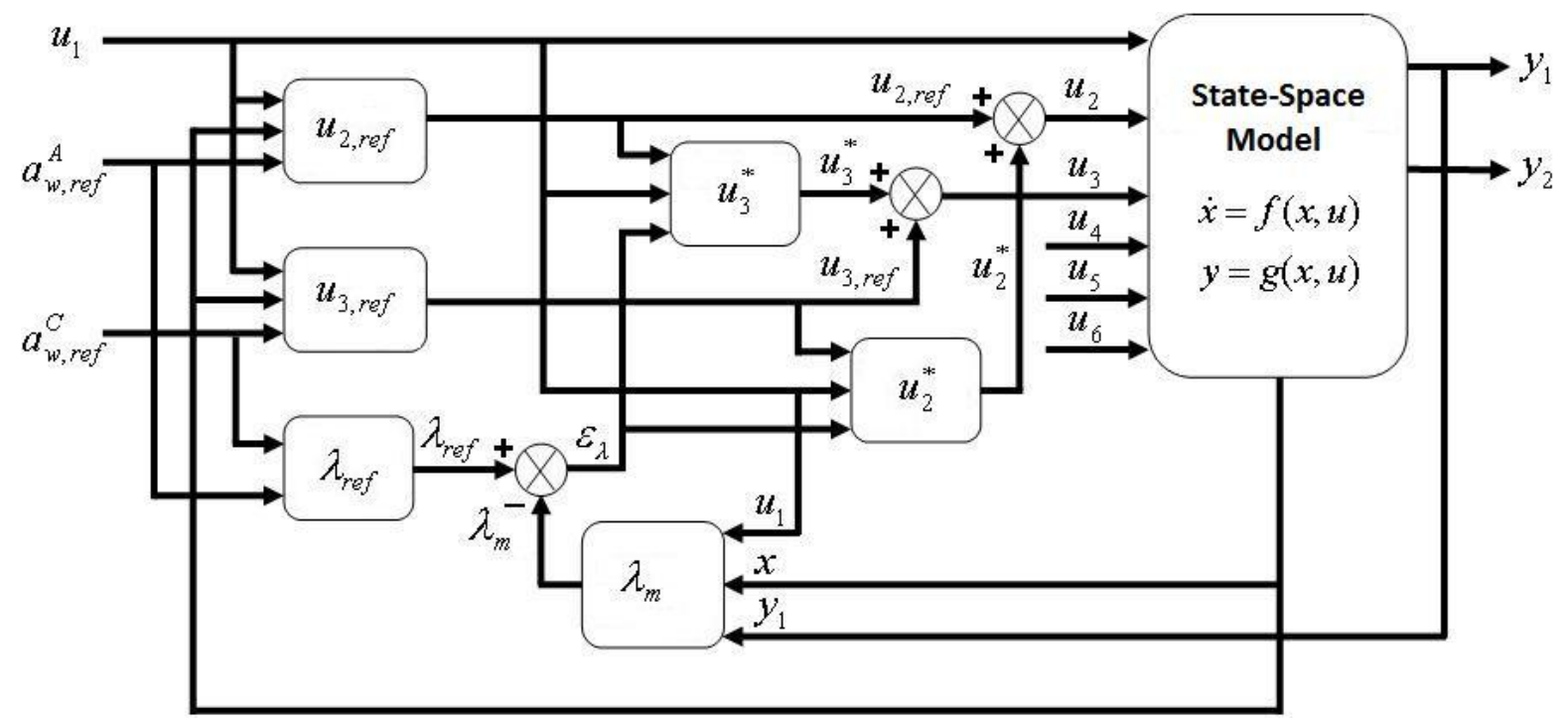

Fig. 1 Block diagram of the regulation process.

anode and cathode sides at convenient levels such that to avoid dry out or flooding of the membrane. For this reason, we aim to have $a_{w}^{A}=a_{w}^{C}=80 \%$ and we determine the inputs $X_{\mathrm{H}_{2} \mathrm{O}}^{\mathrm{A}}$ and $X_{\mathrm{H}_{2} \mathrm{O}}^{\mathrm{C}}$ ensuring these activities. We consider a sinusoidal evolution of $J_{H_{2}}^{A}$ between $J_{H_{2 \min }}^{A}=\frac{j_{0}}{n F}$ and $J_{H_{2 \max }}^{A}=\frac{j_{l}}{n F}$ in order to cover the entire cell operating range (between exchange $j_{0}$ and limit $j_{l}$ current densities).

First, we derive from Eq. (27) in the previous work [1]:

$$
\begin{aligned}
& u_{2, \text { ref }}=\frac{a_{w, r e f}^{A}}{M_{1} u_{1}+M_{2} x_{1}} ; \\
& u_{3, \text { ref }}=\frac{a_{w, r e f}^{A}}{M_{3} u_{1}+M_{4} x_{2}} .
\end{aligned}
$$

where,

$$
\begin{gathered}
M_{1}=\frac{R_{g} T L_{a}}{D_{H_{2}} P_{T_{a n, i n}}^{s a t}} ; \quad M_{2}=\frac{1}{P_{T_{a n, i n}}^{s a t}} ; \\
M_{3}=\frac{R_{g} T L_{c}}{2 D_{O_{2}} P_{T_{c a, i n}}^{s a t}} ; \quad M_{4}=\frac{1}{P_{T_{c a, i n}}^{\text {sat }}} ;
\end{gathered}
$$

The reference membrane water content $\lambda_{\text {ref }}$ is then deduced from Eq. (24) in the previous paper [1] as follows:

$$
\lambda_{\text {ref }}=\frac{\lambda_{\text {ref }}^{A}+\lambda_{r e f}^{C}}{2},
$$

where,

$$
\begin{aligned}
& \lambda_{r e f}^{A}=a_{1}+a_{2} a_{w, \text { ref }}^{A}-a_{3}\left(a_{w, \text { ref }}^{A}\right)^{2}+a_{4}\left(a_{w, \text { ref }}^{A}\right)^{3} ; \\
& \lambda_{\text {ref }}^{C}=a_{1}+a_{2} a_{w, \text { ref }}^{C}-a_{3}\left(a_{w, \text { ref }}^{C}\right)^{2}+a_{4}\left(a_{w, \text { ref }}^{C}\right)^{3} .
\end{aligned}
$$

Now, $\lambda_{m}$ can be calculated from $g$ function given by $y_{1}=g\left(x, u_{1}, \lambda_{m}\right)$ in the state-space model (Eq. (1)):

$$
\begin{aligned}
& \lambda_{m}=h\left(x, u_{1}, y_{1}\right)= \\
& \frac{1}{a_{5}}\left[\frac{2 F L_{m} u_{1}}{E+2 x_{4}-y_{1}-2 A F\left(R_{a}+R_{C}\right) u_{1}}+a_{6}\right] .
\end{aligned}
$$

We emphasis that $u_{2}^{*}$ and $u_{3}^{*}$ depend on the error between $\lambda_{\text {ref }}$ and $\lambda_{m}$. However, $\lambda_{m}$ is a third degree polynomial function (see $\lambda_{m}$ expression in the state-space model). Consequently, its solution with respect to $u_{2}$ and $u_{3}$ is impossible. For this reason, we calculate first $u_{2}^{*}$ by replacing $u_{3}$ with $u_{3, \text { ref }}$, then we state $u_{3}^{*}$ by replacing $u_{2}^{*}$ with $u_{2, \text { ref }}$. Hence, we have to resolve the following relations separately: 


$$
\begin{gathered}
\epsilon_{\lambda}=\lambda_{\text {ref }}-\lambda_{\mathrm{m}}=\mathrm{P}\left(\mathrm{x}_{1}, \mathrm{x}_{2}, \mathrm{u}_{1}, \mathrm{u}_{2}^{*}, \mathrm{u}_{3, \text { ref }}\right) ; \\
\epsilon_{\lambda}=\lambda_{\text {ref }}-\lambda_{\mathrm{m}}=\mathrm{Q}\left(\mathrm{x}_{1}, \mathrm{x}_{2}, \mathrm{u}_{1}, \mathrm{u}_{2, \mathrm{ref}}, \mathrm{u}_{3}^{*}\right) .
\end{gathered}
$$

The solution of these equations gives one real root and two complex roots. Then, the real root of the $P$ function gives:

$$
u_{2}^{*}=\frac{\left[12 C_{4} H_{1 \lambda}+8 C_{3}^{2}\right]^{1 / 3}+4 C_{4}\left(C_{3}^{2}-3 C_{2} C_{4}\right)}{6 C_{4}^{2}\left[12 C_{4} H_{1 \lambda}+8 C_{3}^{2}\right]^{1 / 3}+2 C_{3}},
$$

where,

$$
\begin{aligned}
& H_{1 \lambda}=18\left(\lambda_{r e f}-\lambda_{m}\right) C_{4}-3 C_{2} C_{3}-9 C_{1} C_{4}+\sqrt{F_{1 \lambda}} \\
& F_{1 \lambda}=\left(\lambda_{r e f}-\lambda_{m}\right)\left(12 C_{3}^{2}-54 C_{2} C_{3} C_{4}-162 C_{1} C_{4}^{2}\right)+ \\
& C_{2}^{2}+C_{4}\left(4 C_{2}^{3}+18 C_{1} C_{2} C_{3}+27 C_{1}^{2} C_{4}\right)-C_{3}^{2}\left(4 C_{1}\right) . \\
& C_{1}=\frac{a_{2}}{2}\left[M_{3} u_{1}+M_{4} x_{1}\right] u_{3, r e f}-\frac{a_{3}}{2}\left[M_{3} u_{1}+M_{4} x_{2}\right]^{2} u_{3, r e f}^{2} \\
& +\frac{a_{4}}{2}\left[M_{3} u_{1}+M_{4} x_{2}\right]^{3} u_{3, r e f}^{2}+a_{1} ; \\
& C_{2}=\frac{a_{2}}{2}\left[M_{1} u_{1}+M_{2} x_{1}\right] \\
& C_{3}=\frac{a_{3}}{2}\left[M_{1} u_{1}+M_{2} x_{1}\right]^{2} \\
& C_{4}=\frac{a_{4}}{2}\left[M_{1} u_{1}+M_{2} x_{1}\right]^{3} .
\end{aligned}
$$

Similarly, the real root of the $Q$ function gives:

$$
u_{3}^{*}=\frac{\left[12 C_{8} H_{2 \lambda}+8 C_{7}^{2}\right]^{1 / 3}+4 C_{8}\left(C_{7}^{2}-3 C_{6} C_{8}\right)}{6 C_{8}^{2}\left[12 C_{8} H_{2 \lambda}+8 C_{7}^{2}\right]^{1 / 3}+2 C_{7}},
$$

where,

$$
\begin{aligned}
& H_{2 \lambda}=18\left(\lambda_{\text {ref }}-\lambda_{m}\right) C_{8}-3 C_{6} C_{7}-9 C_{5} C_{8}+\sqrt{F_{2 \lambda}} ; \\
& F_{2 \lambda}=\left(\lambda_{\text {ref }}-\lambda_{m}\right)\left(12 C_{7}^{2}-54 C_{6} C_{7} C_{8}-162 C_{5} C_{8}^{2}\right)+ \\
& C_{6}^{2}+C_{8}\left(4 C_{6}^{3}+18 C_{5} C_{6} C_{7}+27 C_{5}^{2} C_{8}\right)-C_{7}^{2}\left(4 C_{5}\right) . \\
& C_{5}=\frac{a_{2}}{2}\left[M_{1} u_{1}+M_{2} x_{1}\right] u_{2, r e f}-\frac{a_{3}}{2}\left[M_{1} u_{1}+M_{2} x_{1}\right]^{2} u_{2, r e f}^{2} \\
& +\frac{a_{4}}{2}\left[M_{1} u_{1}+M_{2} x_{1}\right]^{3} u_{2, r e f}^{2}+a_{1} ;
\end{aligned}
$$

$$
\begin{aligned}
& C_{6}=\frac{a_{2}}{2}\left[M_{3} u_{1}+M_{4} x_{2}\right] ; \\
& C_{7}=\frac{a_{3}}{2}\left[M_{3} u_{1}+M_{4} x_{2}\right]^{2} ; \\
& C_{8}=\frac{a_{4}}{2}\left[M_{3} u_{1}+M_{4} x_{2}\right]^{3} .
\end{aligned}
$$

Given that, the control laws ensuring constant water activities of $80 \%$ are:

$$
\begin{aligned}
& \bar{u}_{2}=u_{2, r e f}+u_{2}^{*}=\frac{a_{w, r e f}^{A}}{M_{1} u_{1}+M_{2} x_{1}}+u_{2}^{*} ; \\
& \bar{u}_{3}=u_{3, \text { ref }}+u_{3}^{*}=\frac{a_{w, r e f}^{C}}{M_{3} u_{1}+M_{4} x_{2}}+u_{3}^{*} .
\end{aligned}
$$

Fig. 2 presents the control inputs $\bar{u}_{2}$ and $\bar{u}_{3}$ that ensure static water activities in case of sinusoidal power demand represented by $J_{H_{2}}^{A}$. One can observe that $\bar{u}_{2}$ and $\bar{u}_{3}$ behave conversely to $J_{H_{2}}^{A}$. This is due to the fact that we need to humidify less when $J_{H_{2}}^{A}$ increases and vice versa because the water production at the cathode side is proportional to gas flow rates. Fig. 2 shows also that $a_{w}^{A}, a_{w}^{C}$ and $\lambda_{m}$ are constants and at their desired values. Hence, the proposed control laws $\bar{u}_{2}$ and $\bar{u}_{3}$ provide a good regulation.

Fig. 3 shows that the output current density $j$ behaves proportionally to the hydrogen flow rate $u_{1}$

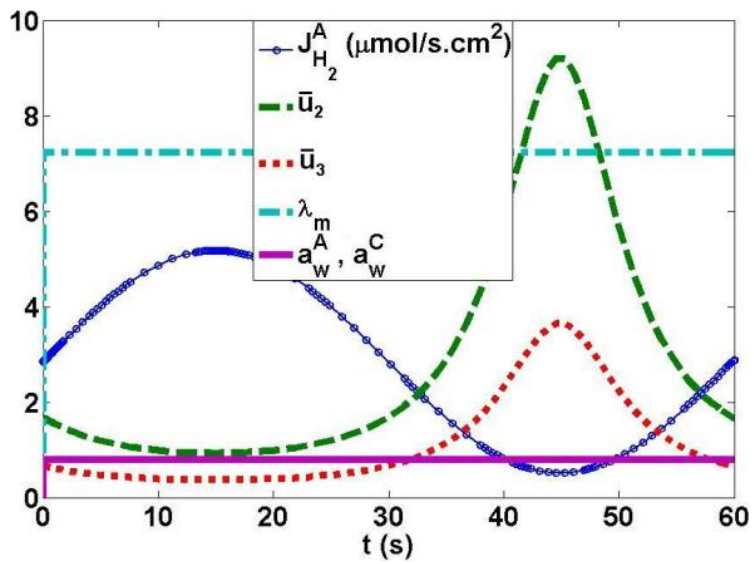

Fig. 2 Static water activities control. 


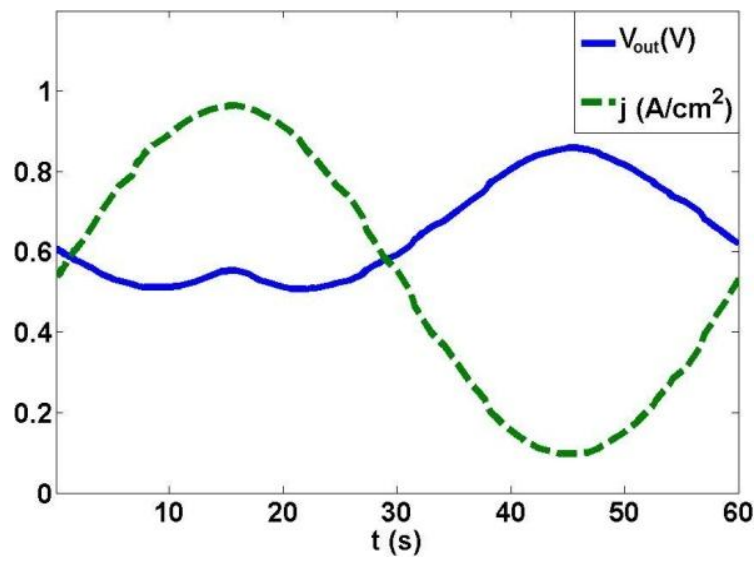

Fig. 3 Responses of electrical outputs for static water activities control.

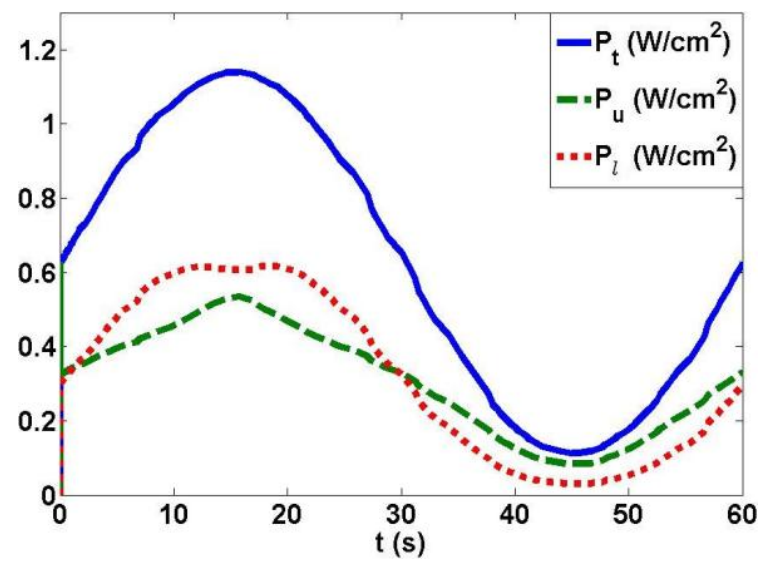

Fig. 4 Responses of powers for static water activities control.

while the output voltage $V_{\text {out }}$ is conversely proportional to it. This is in accord with fuel cell operating principle since voltage losses are proportional to the current. Furthermore, Fig. 4 reveals an overflow of the lost power $P_{l}$ with respect to the useful power $P_{u}$ in the zone of high power demand. This is due to the high voltage drop caused by the current increase. Therefore, simulation results show that maintaining constant water activities in variable operating power is not optimum for the fuel cell's efficiency.

\subsection{Control for Dynamic Water Activities}

In order to improve fuel cell's efficiency in variable operating power (case of automotive applications), we are going to build in this part a control providing an appropriate dynamical evolution for water activities.
In particular, we propose a sinusoidal variation of $a_{w}^{A}$ and $a_{w}^{C}$ similar to $J_{H_{2}}^{A}$. The desired variations of $a_{w}^{A}$ and $a_{w}^{C}$ are supposed to be between $60 \%$ and $100 \%$ to avoid dry out or flooding of the membrane.

Since we consider a sinusoidal power demand, $u_{1}$ can be written in the following form:

$$
u_{1}=k_{1} \sin (\omega t)+k_{2} \text {, }
$$

with

$$
k_{1}=\frac{u_{1 \max }-u_{1 \min }}{2} ; \quad k_{2}=\frac{u_{1 \max }+u_{1 \min }}{2} .
$$

The objective of the control aims to have reference water activities similar to $u_{1}$. Therefore,

$$
a_{w, \text { ref }}=M_{5} \sin (\omega t)+M_{6} \text {, }
$$

with

$$
\begin{aligned}
& M_{5}=\frac{\left(a_{w, \text { ref }}\right)_{\max }-\left(a_{w, \text { ref }}\right)_{\min }}{2} ; \\
& M_{6}=\frac{\left(a_{w, \text { ref }}\right)_{\max }+\left(a_{w, \text { ref }}\right)_{\min }}{2} .
\end{aligned}
$$

Introducing time-phasing between $a_{w, r e f}^{A}$ and $a_{w, r e f}^{C}$, we can write:

$$
\begin{aligned}
& a_{w, \text { ref }}^{A}=M_{5} \sin (\omega t)+M_{6}=k_{3} u_{1}+k_{4} ; \\
& a_{w, \text { ref }}^{C}=M_{5} \sin (\omega t+\phi)+M_{6} .
\end{aligned}
$$

with

$$
\begin{aligned}
& k_{1}=\frac{M_{5}}{k_{1}} ; \\
& k_{4}=M_{6}-\frac{M_{5} k_{2}}{k_{1}} .
\end{aligned}
$$

Hence, the appropriate control laws $\left(\tilde{u}_{2}\right.$ and $\left.\tilde{u}_{3}\right)$ for sinusoidal water activities are calculated according to Eqs. (2) and (11) as follows:

$$
\begin{aligned}
& \tilde{u}_{2}=\frac{k_{3} u_{1}+k_{4}}{M_{1} u_{1}+M_{2} x_{1}}+u_{2}^{*} ; \\
& \tilde{u}_{3}=\frac{M_{5} \sin (\omega t+\phi)+M_{6}}{M_{3} u_{1}+M_{4} x_{2}}+u_{3}^{*} .
\end{aligned}
$$


Figs. 5 and 6 present the control inputs applied to the model for static and dynamic water activities with different time-phasing. The results in Fig. 7 show an exact regulation of the water activities with respect to their desired variations and time-phasing. In particular, simulations show that static control inputs $\bar{u}_{2}$ and $\bar{u}_{3}$ results in constant water activities of $80 \%$ as desired. Dynamic control inputs $\tilde{u}_{2}$ and $\tilde{u}_{3}$ results in sinusoidal water activities varying between $60 \%$ and $100 \%$ as also desired. Furthermore, the proposed control inputs related to the desired time-phasing $\phi$ ensure an exact regulation of $a_{w}^{A}$ and $a_{w}^{C}$ for $\phi=0, \phi=\frac{\pi}{3}, \phi=\frac{\pi}{2}$ and $\phi=\pi$.

In Fig. 8 we simulate the evolution of the electrical efficiency with respect to the power demand.

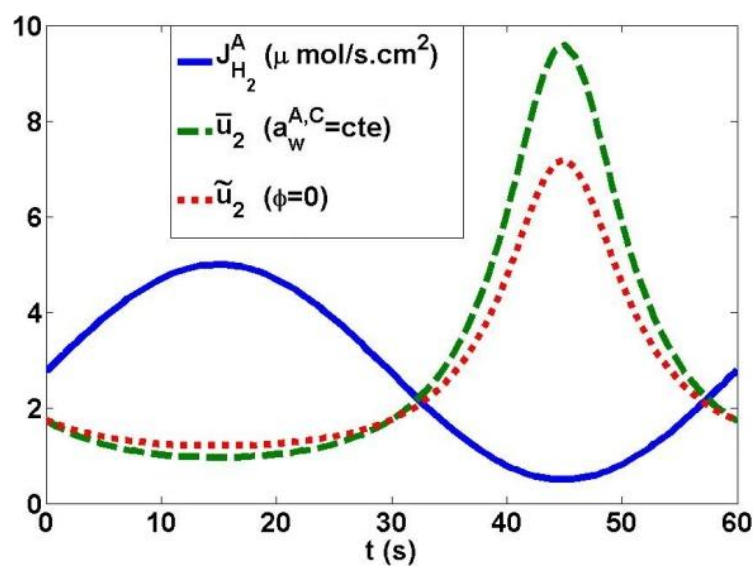

Fig. 5 Static versus dynamic control of water mole fraction in hydrogen.

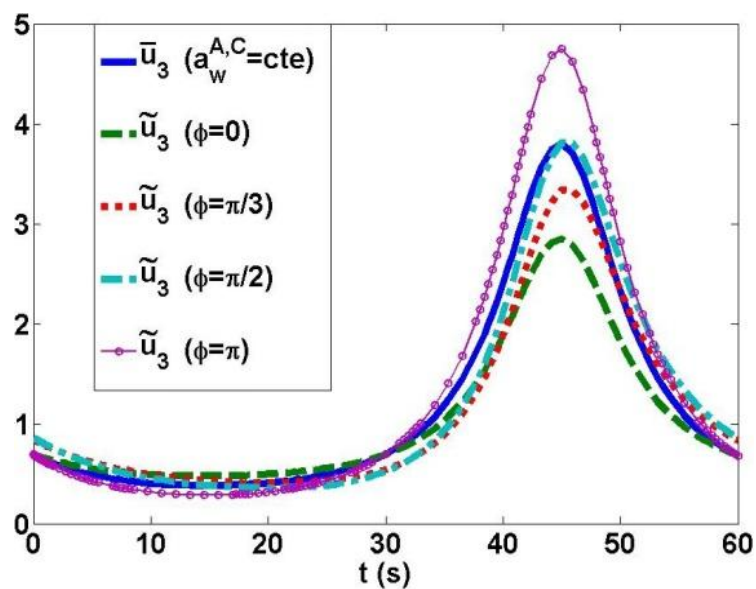

Fig. 6 Static versus dynamic control of water mole fraction in oxygen with different time-phasing.

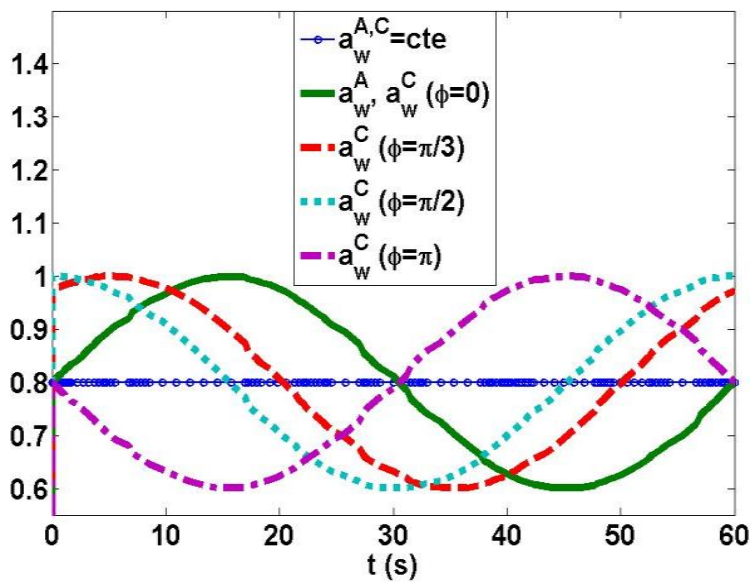

Fig. 7 Anode and cathode water activities for static and dynamic control with different time-phasing.

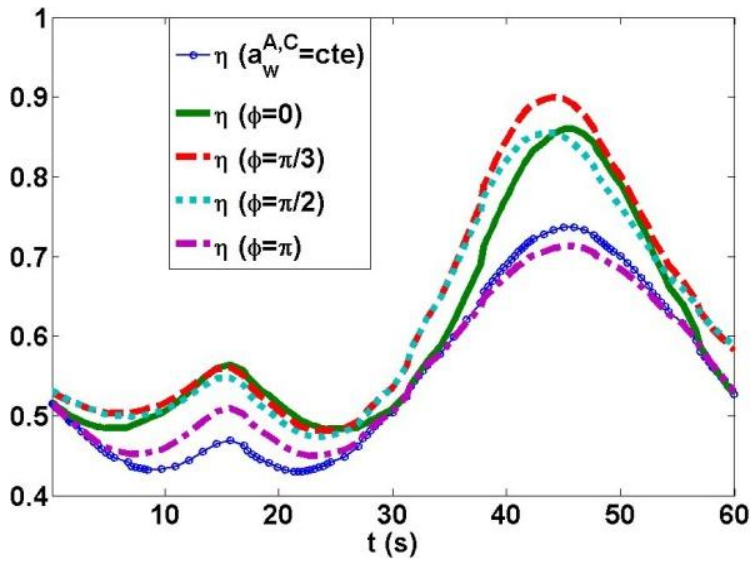

Fig. 8 Electrical efficiency variation with respect to the power demand-comparision between static and dynamic control with different time-phasing.

First of all, we notice that the efficiency is conversely proportional to the power demand. Indeed, for high power demand the current generated by the fuel cell is large and so are the losses. In opposition, when the power demand is low the losses are also low and therefore the efficiency is higher. Second, the simulation shows that dynamic control of water activities ensure better efficiency comparing to static control. In addition, the result proved that the best dynamic efficiency is obtained for a time-phasing of $\frac{\pi}{3}$ between anode and cathode water activities.

In conclusion, simulation results show that static humidity control do not provide optimum efficiency especially in case of dynamic power demand such as in automotive applications. A better control consists 
of dynamic humidity regulation similar to the power demand evolution. Furthermore, time-phasing between anode and cathode water activities plays an important role in the efficiency improvement and its best value is $\phi=\frac{\pi}{3}$. It should be noted that this value is drawn from simulations and do not represent the optimal value. However, it shows that taking into account time-phasing between water activities make an important improvement in fuel cell's efficiency up to $20 \%$ as shown in Fig. 8 .

\section{Conclusion}

In this work, an innovative strategy of humidity control in PEM fuel cells is proposed. It consists on regulating gas humidification rates according to the power demand so that to improve fuel cell's dynamic efficiency. The proposed control uses the model of Ref. [1] to calculate the membrane's water content thereby solving the problem of placing a humidity sensor inside the cell. Humidification constraints are taken into account to avoid dry out or flooding of the membrane. Control for static and dynamic water activities are examined. Simulation results show that static humidity regulation do not provide optimum efficiency in case of dynamic power demand. A better regulation consists of dynamic humidity regulation similar to the power demand variation. Furthermore, effect of time-phasing between anode and cathode water activities is studied. Simulations results prove that time-phasing plays an important role in minimizing power losses. Results show a significant improvement in fuel cell's efficiency up to $20 \%$ for a time-phasing of $\frac{\pi}{3}$.

\section{References}

[1] Haddad, A., Elsoufi, L., Mannah, M., and Bazzi, H. 2015. "Control-Oriented Mathematical Modeling of Humidity in PEM Fuel Cells." Journal of Control Science and Engineering 3 (3): 164-78.

[2] Kulikovsky, A. A. 2001. "Quasi Three-Dimensional Modeling of the PEM Fuel Cell: Comparison of the
Catalyst Layers Performance.” Fuel Cells 1: 162-9.

[3] Rowe, A., and Li, X. 2001. "Mathematical Modeling of Proton Exchange Membranefuel Cells." Journal of Power Sources 102 (1-2): 82-96.

[4] Bradean, R., Promislow, K., and Wetton, B. 2001. "Heat and Mass Transfer in Porousfuel Cell Electrodes." In Proceedings of the International Symposium on Advances in Computational Heat Transfer, 969-76.

[5] Pisani, L., Murgia, G., Valentini, M., and Aguanno, B. D. 2002. "A New Semi-Empirical Approach to Performance Curves of Polymer Electrolyte Fuel Cells." Journal of Power Sources 108 (1-2): 192-203.

[6] Marr, C., and Li, X. 2004. “An Engineering Model of Proton Exchange Membrane Fuel Cell Performance." ARI 50 (4): 190-200.

[7] Gurau, V., Liu, H., and Kaka, S. 2004. "Separation Two-Dimensional Model for Proton Exchange Membrane Fuel Cells." American Institute of Chemical Engineers Journal 44: 2410-22.

[8] Moya, A. A. 2012. "Electric Circuits Modelling the Low-Frequency Impedance of Ideal Ion-Exchange Membrane Systems.” Electrochimica Acta 62: 296-304.

[9] Saadi, A., Becherif, M., Aboubou, A., and Ayad, M. Y. 2013. "Comparison of Pro-Ton Exchange Membrane Fuel Cell Static Models.” Renewable Energy 56: 64-71.

[10] Lachaize, J. 2004. "Study of Strategiesand Control Structures Fordrivingtraction Fuel Cell's Power Systems." Ph.D. thesis, Laboratory of Electrotechnics and Industrial Electronics, ENSEEIHT, Toulouse.

[11] Caux, S., Lachaize, J., Fadel, M., Shott, P., and Nicod, L. 2005. "Modeling and Control of a Fuel Cell System and Storage Elements in Transport Applications." Journal of Process Control 15 (4): 481-91.

[12] Mueller, F., Brouwer, J., Kang, S., Kim, H., and Min, K. 2007. "Quasi-Three Dimen-Sional Dynamic Model of a Proton Exchange Membrane Fuel Cell for System and Controls Development." Journal of Power Sources 163 (2): 814-29.

[13] Sharifi Asl, S. M., Rowshanzamir, S., and Eikani, M. H. 2010. "Modelling and Simulation of the Steady-State and Dynamic Behaviour of a PEM Fuel Cell." Renewable Energy 35 (4): 1633-46.

[14] Yerramalla, S., Davari, A., Feliachi, A., and Biswas, T. 2003. "Modeling and Simulation of the Dynamic Behavior of a Polymer Electrolyte Membrane Fuel Cell.” Journal of Power Sources 124 (1): 104-13.

[15] Pukrushpan, J., Peng, H., and Stefanopoulou, A. 2004. "Control-Oriented Modeling and Analysis for Automotive Fuel Cell Systems." Journal of Dynamic Systems, Measurement and Control 126 (1): 14-25.

[16] Ziogou, C., Voutetakis, S., Papadopoulou, S., and Georgiadis, M. 2010. "Modeling and Experimental 
Validation of a Pem Fuel Cell System." 20th European Symposium on Computer Aided Process Engineering.

[17] Shen, C., Cao, G. Y., and Zhu, X. J. 2002. "Nonlinear Modeling of MCFC Stack Based on RBF Neural Networks Identification." Simulation Modelling Practice and Theory 10 (1-2): 109-19.

[18] Shen, C., Cao, G. Y., Zhu, X. J., and Sun, X. J. 2002. "Nonlinear Modeling and Adaptive Fuzzy Control of MCFC Stack." Journal of Process Control 12 (8): 831-9.

[19] Golbert, J., and Lewin, D. 2004. "Model-Based Control of Fuel Cells: Regulatory Control." Journal of Power Sources 135: 135-51.

[20] Shen, C. 2004. "Control-Oriented Nonlinear Modelling of Molten Carbonate Fuel Cells." International Journal of Energy Research 28: 403-10.

[21] Mangold, M., Krasnyk, M., and Sundmacher, K. 2004. "Nonlinear Analysis of Current Instabilities in High Temperature Fuel Cells." Chemical Engineering Science 59 (22-23): 4869-77.

[22] Sun, T., Cao, G., and Zhu, X. 2005. "Nonlinear Modeling of PEMFC Based on Neural Networks Identification." Journal of Zhejiang University Science A 6: $365-70$.
[23] Qi, Y., Huang, B., and Chuang, K. 2005. "Dynamic Modeling of Solid Oxide Fuel Cell: The EECT of Diffusion and Inherent Impedance." Journal of Power Sources 150: 32-47.

[24] Shokuhi-Rad, A., Jamali, A., Naghashzadegan, M., Nariman-zadeh, N., and Hajiloo, A. 2012. "Optimum Pareto Design of Non-linear Predictive Control with Multi-design Variables for PEM Fuel Cell.” International Journal of Hydrogen Energy 37 (15): 11244-54.

[25] Wang, Y., and Wang, C. 2005. "Transient Analysis of Polymer Electrolyte Fuel Cells." Electrochemica Acta 50 (6): 1307-15.

[26] Wang, Y., and Wang, C. 2007. "Two Phase Transients of Polymer Electrolyte Fuel Cells." Journal of the Electrochemical Society 154 (7): 636-43.

[27] Fuller, T., and Newman, J. 1992. "Experimental Determination of the Transport Number of Water in Nafion 117 Membrane." Journal of the Electrochemical Society 139 (5): 1332-7.

[28] Okada, T., Xie, G., and Tanabe, Y. 1996. "Theory of Water Management at the Anode Side of Polymer Electrolyte Fuel Cell Membranes." Journal of Electroanalytical Chemistry 413 (1-2): 49-65. 